\title{
Empirical Study on the Relationship Between "Internet+" Logistics Parks and County Economy: Taking Huanggang County as an Example
}

\author{
Meng-ni Xiong ${ }^{1}$, Wen-jing You ${ }^{1}$ and Xing-jian Zhou ${ }^{1,2, *}$ \\ ${ }^{1}$ School of Management, Wuhan Textile University, Wuhan, China \\ ${ }^{2}$ Research Center of Enterprise Decision Support, Hubei Province Research Base for Humanities and Social Sciences, \\ Wuhan, China \\ Email: wuliuwtu@163.com
}

\begin{abstract}
Internet + " allows resources and elements to flow freely in a fictitious way, which has an important impact on the development of county economy. Studying the relationship between logistics park and county economic development under the "Internet +", we can better understand the operation status, roles and influences of "Internet + logistics" in the county economy. Taking the county economy of Huanggang, Hubei Province as an example, by using Grainger causality test and impulse response analysis, the four time series variables of fixed assets investment, logistics volume, logistics added value and Gross Regional Product were analyzed and demonstrated. Under the "logistics+", the logistics Park and county economy development exists interactive relationship, and which proposals some advises for the development of county logistics industry in Huanggang.
\end{abstract}

Keywords: "Internet + logistics", logistics park, county economy, Grainger causality test, impulse response analysis

\section{“互联网+”下物流园区与县域经济发展关系实证研究}

\author{
熊孟妮 ${ }^{1}$, 尤文静 ${ }^{2}$, 周兴建 ${ }^{1,} 2^{*}$ \\ 1 武汉纺织大学 管理学院, 武汉 \\ 2 湖北省人文社会科学研究基地 企业决策支持研究中心, 武汉 \\ Email: wuliuwtu@163.com
}

\begin{abstract}
摘要: “互联网+”让资源和要素以虚拟的方式进行自由无阻的流通，对县域经济发展产生重要的影 响。研究 “互联网+” 下物流园区与县域经济发展的关系, 能够更好的了解 “互联网+物流” 在县域 经济中的运营状况及其在县域经济发展中的作用与影响力。以湖北省黄冈市县域经济为例, 通过运 用格兰杰（Granger）因果关系检验和脉冲响应分析对县域物流园区固定资产投资、物流量、物流增 加值和地区生产总值等四个时间序列变量进行因果分析，实证分析和论证了“互联网+”下物流园区 与县域经济的互动发展关系, 并为黄冈市县域物流业发展提出相关建议。
\end{abstract}

关键词：“互联网+物流”，物流园区，县域经济，格兰杰因果检验，脉冲响应分析

\section{1 引言}

物流业在促进及维持经济平稳运行当中起着重要的作用 ${ }^{[1]}$ 。物流对于促进资源要素的合理配置, 优化区 域经济产业结构, 增强区域经济实力和整体竞争力等方面有着十分重要的理论和现实意义。在区域经济 发展中, 物流园区是一个重要的基础、纽带和载体 ${ }^{[2]}$, 其通过园区设施带来的扩散效应对区域经济一体 化发展施加重要的影响。这其中，县域经济是区域经济发展中的基石 ${ }^{[3]}$ ，县域物流园区承接区域中心城 市的物流能力辐射，是区域经济真正一体化的末端关键组成部分。但是，对于以农业经济为主体以及当 前农村物流发展现状来看, 由于县域的地理特征, 生产场地、物流设施及市场需求较为分散, 县域物流 
园区对资源的配置能力及对经济发展的协调作用较弱, 对县域经济贡献效果甚微。随着互联网信息技术 的发展和成熟, 互联网平台为资源和要素以虚拟的方式进行自由无阻的流通提供了可能的途径, 研究 “互联网+”下物流园区与县域经济发展的关系也就成为一个亟待解决的问题。

\section{2 文献回顾}

现有关于物流园区与区域经济之间关系的文献, 主要集中在物流产业、物流园区投资及物流基础设施等 三个方面与区域经济及区域物流之间的关系研究上。

物流产业、物流园区与区域物流之间的关系研究。如, 李剑等（2016）[4]选取 2004-2013 年我国内 地 31 个省际数据为样本, 运用空间计量模型实证分析物流产业集聚对区域经济增长的影响; 陶经辉等 （2017）[5]运用系统动力学理论构建"ILSD"模型,分析物流园区与产业园区在 GDP、第三产业产值以及 进口交易额和出口交易额等四个方面的联动关系; 叶羽等（2018）基于增长极理论,从产业集聚、城市 功能分区、城市环境、社会贡献四个角度研究物流园区对区域经济的影响关系; 郭湖斌等 (2018) [7]构 建区域物流与区域经济协调发展的评价指标体系,运用耦合度模型对长三角地区 2001 2016 年间区域物 流与区域经济发展的耦合协调性进行实证分析; 朱长征等（2018） ${ }^{88}$ 以 2001-2014 年我国 4 个直辖市和 15 个副省级城市的数据为基础,应用物流产业区位熵指数对物流产业集聚度进行了分析。同时,采用面板 数据模型剖析了物流产业集聚对城市经济的影响效应。

物流园区投资与区域经济发展的关系研究，如，刘明菲（2007）[9]通过收集武汉市十年来 GDP、 物流产值和物流园区固定设施投资的数据分析物流园区投资对区域经济弹性影响大小以及区域经济对物 流业推动程度; 胡凯等 (2012） ${ }^{[10]}$ 重点分析了中部地区物流基础设施投资与经济发展的关系, 并通过格 兰杰因果关系检验论证了物流基础设施投资只能单向促进区域经济发展; 刘俊华等（2013） ${ }^{[11]}$ 运用系统 动力学模型对我国近年物流基础设施建设投资与经济增长之间的内在作用机制进行模型构建与拟合,提 出物流基础建设与经济增长之间具有长期稳定的均衡关系, 认为在继续增加物流基础设施投资的同时, 要关注提高现有物流基础设施资源的使用效率; 王欢欢（2015） [12]分析了物流投资中区域之间的联系、 物流增值和 GDP 3 个变量之间的协整关系, 提出在物流基础设施的投资中存在 GDP 的格兰杰因果关 系。

物流园区基础设施、运营模式与区域经济的关系研究。如, Taylor（2012）[13]从物流基础设施的视 角研究物流与区域经济的关系, 分析了物流基础设施与区域经济发展的相关性, 其结论表明物流设施的 可达性对区域经济发展有显著的影响，而区域经济的发展也会促进物流设施的建设; Ozmen（2016）[14] 从公路运输角度阐释物流与区域经济的关系, 通过构建 Granger 因果检验法探讨了公路运输与区域经济 发展机制, 提出公路运输与区域经济发展之间存在显著的正相关性。刘春雷、薛宝佳等 (2017) ${ }^{[15]}$ 研究 了临空物流与区域经济的协同效益, 通过计量经济学模型论证临空物流与区域经济互为因果并相互促进 发展。

现有的研究主要集中于从宏观上针对物流或经济的某一环节或某一层面进行研究, 同时对两者之间 的动态作用机理也缺乏定量的论证。尤其是在“互联网+”的背景下，基于互联网的物流园区与区域经济 之间的关系研究, 更是鲜有文献涉及。因此, 本文试图从中、微观的角度, 以黄冈市各县为背景, 实证 分析“互联网+”下物流园区与县域经济之间的关系, 以为促进县域经济与县域物流能够联动发展、相辅 相成。

\section{3 实证分析}

\section{1 变量的选取和说明}

本文在考虑数据的可得性和连续性的基础上，选取了 2006-2016 年黄冈市县域（黄州、武穴、麻城、 红安、罗田、英山、浠水、蒴春、黄梅、团风）的物流园区固定资产投资、物流量（货物周转量）、物 流增加值 3 个时间序列变量作为 “互联网+物流”的衡量指标, 分别记为 TZ、HWZ、ZJ 和 GDP。县域 经济的衡量指标则为地区生产总值 (GDP)。货物运输是 “互联网+物流”的关键要素，而园区货物周转 量又是衡量物流业发展程度的核心指标, 因此选用物流量（园区货物周转量）具有一定的可替代性, 由 于园区物流增加值尚未有统一的衡量标准, 选用交通运输、仓储及邮电业增加值作为其替代指标 ${ }^{[16]}$, 物 流园区固定资产投资和园区物流增加值则从经济层面反应“互联网+物流”的发展程度。

根据黄冈市统计年鉴 (2006-2016 年) , 相关统计数据如表 1 所示。同时, 为了达到数据的平稳性 和消除物价等因素对数据的影响, 本文对以上四个变量取对数, 并依次记为 LOGTZ、LOGHWZ、 LOGZJ 和 LOGGDP。 
表 1. 黄冈市县域经济统计数据表（2006-2016 年）

\begin{tabular}{|c|c|c|c|c|}
\hline 年份 & GDP & 园区物流量 & 物流园区固定资产投资 & 园区物流增加值 \\
\hline 2006 & 241.45 & 6.18 & 12.37 & 14.57 \\
\hline 2007 & 285.73 & 13.8 & 16.82 & 16.91 \\
\hline 2008 & 370.59 & 24.13 & 23.82 & 22.35 \\
\hline 2009 & 437.6 & 27.94 & 30.83 & 23.27 \\
\hline 2010 & 512.38 & 44.09 & 40.94 & 24.57 \\
\hline 2011 & 611.48 & 56.63 & 47.92 & 26.79 \\
\hline 2012 & 710.95 & 78.76 & 61.89 & 28.94 \\
\hline 2013 & 815.02 & 111.09 & 77.98 & 30.49 \\
\hline 2014 & 912.3 & 185.16 & 90.4 & 31.83 \\
\hline 2015 & 990.74 & 212.96 & 99.76 & 33.27 \\
\hline 2016 & 1086.55 & 218.88 & 110.95 & \\
\hline
\end{tabular}

（资料来源：黄冈市统计年鉴（2006-2016 年））

\section{2 格兰杰因果关系检验}

\section{1. 单位根检验}

应用 eviews6.0 对数据进行单位根及协整检验 ${ }^{[17]}$ 。从图 1 中可以看出, 黄冈市七县的物流园区固定 资产投资、园区物流量、园区物流增加值和 GDP 都呈现持续上升的趋势, 四者之间存在较为稳定的相 关关系, 为了定量验证其平稳性, 本文采用单位根（ADF）检验来判断四者之间的平稳情况, 如表 2 所 示。

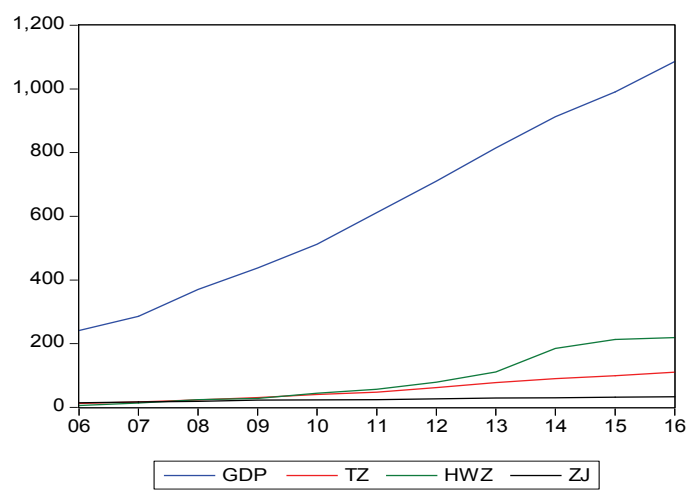

图 1. GDP、TZ、HWZ 和 ZJ 的线形图

表 2. ADF 单位根检验结果

\begin{tabular}{ccccc}
\hline Series & Prob. & Lag & Max Lag & Obs \\
\hline LOG(GDP) & 0.1328 & 0 & 1 & 10 \\
LOG(TZ) & 0.4254 & 0 & 1 & 10 \\
LOG(HWZ) & 0.7636 & 0 & 1 & 10 \\
LOG(ZJ) & 0.6113 & 0 & 1 & 10 \\
DLOG(GDP) & 0.1930 & 0 & 1 & 9 \\
DLOG(TZ) & 0.5816 & 0 & 1 & 9 \\
DLOG(HWZ) & 0.2604 & 1 & 1 & 8 \\
DLOG(ZJ) & 0.2452 & 1 & 1 & 7 \\
DLOG(GDP,2) & 0.2238 & 1 & 1 & 8 \\
DLOG(TZ,2) & 0.1923 & 0 & 1 & 8 \\
DLOG(HWZ,2) & 0.2923 & 0 & 1 & 7 \\
DLOG(ZJ,2) & 0.1396 & 1 & 1 &
\end{tabular}


对表 2 中四个时间序列变量分别取原序列、一阶差分和二阶差分后的概率值均大于 $5 \%$ 显著性水平 下的概率值 0.05 , 该时间序列数据通过 $\mathrm{ADF}$ 单位根检验, 即物流园区固定资产投资、园区物流量、园 区物流增加值和地区生产总值四个序列变量之间存在着平稳关系, 因此可以对数据进行协整分析。

2. 协整关系检验

由于本文涉及三个以上的变量, 因此采用 Johansen 检验对变量之间的协整关系进行分析 ${ }^{[18]}$, 其检 验结果如表 3 所示。

表 3. Johansen 协整检验结果

\begin{tabular}{ccccc}
\hline Series & LOG(GDP) & LOG(TZ) & LOG(HWZ) & LOG(ZJ) \\
\hline $\begin{array}{c}\text { Hypothesized } \\
\text { No. of CE }\end{array}$ & Eigen value & $\begin{array}{c}\text { Trace } \\
\text { statistics }\end{array}$ & $\begin{array}{c}0.05 \text { Critical } \\
\text { value }\end{array}$ & Prob \\
\hline None & 0.675146 & 40.36554 & 29.79707 & 0.0021 \\
At most 1 & 0.350248 & 10.68563 & 15.49471 & 0.3266 \\
At most 2 & 0.075683 & 2.13176 & 3.841466 & 0.1877 \\
\hline
\end{tabular}

Johansen 协整检验结果的判断主要是通过计算迹统计量 Trace-statistics 和特征值 Eigen value 并与 0.05 置信水平下的临界值进行比较。根据表 2 , 第一行的迹统计量 40.36554 大于 0.05 置信水平下的临 界值 29.79707, 则可拒绝原假设, 即变量之间存在协整关系。而第二行和第三行的迹统计量均小于 0.05 置信水平下的临界值, 则接受原假设, 说明 GDP、物流园区固定资产投资、园区物流量和园区物流增 加值四组变量之间存在至少一个协整关系。因此, 可以利用格兰杰检验对四组变量进行因果关系分析。 3. 格兰杰因果关系检验

对 GDP、物流园区固定资产投资、园区物流量和园区物流增加值进行格兰杰因果检验 ${ }^{[19]}$, 并选择 滞后期为 1 至 2 阶，自由度为 10 个。其检验结果如表 4 所示。

表 4. 格兰杰因果关系检验结果

\begin{tabular}{|c|c|c|c|}
\hline Null Hypothesis & obs & F-Statistic & Prob. \\
\hline TZ does not Granger Cause GDP & 10 & 3.36598 & 0.0092 \\
\hline GDP does not Granger Cause TZ & & 15.8052 & 0.0054 \\
\hline HWZ does not Granger Cause GDP & 10 & 5.51895 & 0.0511 \\
\hline GDP does not Granger Cause HWZ & & 6.41422 & 0.0391 \\
\hline ZJ does not Granger Cause GDP & 10 & 3.11521 & 0.1209 \\
\hline GDP does not Granger Cause ZJ & & 1.49136 & 0.2615 \\
\hline HWZ does not Granger Cause TZ & 10 & 7.71989 & 0.0274 \\
\hline TZ does not Granger Cause HWZ & & 11.9996 & 0.0105 \\
\hline ZJ does not Granger Cause TZ & 10 & 4.28203 & 0.0773 \\
\hline TZ does not Granger Cause ZJ & & 0.39360 & 0.5503 \\
\hline ZJ does not Granger Cause HWZ & 10 & 3.71561 & 0.0953 \\
\hline HWZ does not Granger Cause ZJ & & 0.09169 & 0.7708 \\
\hline TZ does not Granger Cause GDP & 9 & 1.80401 & 0.2764 \\
\hline GDP does not Granger Cause TZ & & 4.78371 & 0.0869 \\
\hline HWZ does not Granger Cause GDP & 9 & 3.44646 & 0.1348 \\
\hline GDP does not Granger Cause HWZ & & 2.80110 & 0.1735 \\
\hline ZJ does not Granger Cause GDP & 9 & 0.50904 & 0.6354 \\
\hline GDP does not Granger Cause ZJ & & 11.3542 & 0.0224 \\
\hline HWZ does not Granger Cause TZ & 9 & 2.87672 & 0.1682 \\
\hline TZ does not Granger Cause HWZ & & 4.90956 & 0.0838 \\
\hline ZJ does not Granger Cause TZ & 9 & 0.72787 & 0.5375 \\
\hline TZ does not Granger Cause ZJ & & 0.39783 & 0.6957 \\
\hline ZJ does not Granger Cause HWZ & 9 & 2.17630 & 0.2293 \\
\hline HWZ does not Granger Cause ZJ & & 0.04157 & 0.9597 \\
\hline
\end{tabular}


根据格兰杰因果关系检验的判断准则, 表 4 中 GDP 不是 TZ 的 Granger 因, TZ 不是 GDP 的 Granger 因, GDP 不是 HWZ 的 Granger 因, HWZ 不是 TZ 的 Granger 因, TZ 不是 HWZ 的 Granger 因, GDP 不是 ZJ 的 Granger 因; 剩下的则为接受原假设。也即“互联网+物流”与县域经济的关系具体 表现在以下几个方面:

（1）园区物流增加值不是县域 GDP 增长的格兰杰原因, 说明园区物流增加值并不能有效促进县 域经济的发展, 但在滞后期 2 阶时, 县域 GDP 是园区物流增加值的单向格兰杰原因, 说明县域经济的 发展与繁荣能够带动园区物流增加值的提升, 也能证实县域经济的发展能够推动物流业产值的增加。

（2）县域 GDP 增长与物流园区固定资产投资是双向的格兰杰原因, 说明经济的发展能够推动物 流园区固定资产投资额的增加，物流园区方面的投资也能对县域经济发展起到较为显著的促进作用。

(3) 在 1 阶滞后期时, 县域 GDP 增长是园区物流量的单向格兰杰原因, 但在 2 阶时, 两者之间 不存在格兰杰原因, 说明县域经济增长对园区物流量的提升存在弱向的促进作用; 滞后期 1 阶时, 园区 物流量与物流园区固定资产投资存在双向的格兰杰原因, 物流园区投资的增加能够有效提升物流量, 而 园区物流量的积累与集聚能够给县域物流带来更多的投资, 进而促进县域物流业的发展; 无论在 1 阶还 是 2 阶滞后期的条件下, 园区物流增加值与园区物流量, 园区物流增加值与物流园区投资之间不存在格 兰杰原因，两者之间没有相互促进的作用。

\section{3 脉冲响应分析}

为加强格兰杰因果检验的可靠性, 对检验结果进行脉冲响应分析。根据格兰杰因果检验结果, 物流园区 固定资产投资、园区物流增加值与县域经济 (GDP) 之间存在单向或双向的格兰杰原因, 因此对这三 个变量进行脉冲响应分析。

1. VAR 模型建立

将物流园区固定资产投资、园区物流增加值与县域经济（GDP）三组变量作为VAR模型变量进行 分析, 其结果如下表 5 所示。

表 5. VAR 模型检验结果

\begin{tabular}{cccccccc}
\hline 变量 & 滞后期 & 估计值 & 标准差 & $\mathrm{T}$ 值 & $\mathrm{R}$ 方 & $\mathrm{AIC}$ & $\mathrm{SC}$ \\
\hline $\mathrm{GDP}$ & 1 & 1.183653 & 0.37070 & 3.19305 & 0.998164 & 8.461205 & 8.582239 \\
$\mathrm{TZ}$ & 1 & 0.031115 & 0.32069 & 0.09703 & 0.997610 & 4.505447 & 4.626481 \\
$\mathrm{ZJ}$ & 1 & 0.429753 & 0.21691 & 1.98121 & 0.994371 & 1.749192 & 1.870226 \\
$\mathrm{GDP}$ & 2 & 1.457840 & 0.40748 & 3.57795 & 0.997550 & 8.660903 & 8.748558 \\
$\mathrm{TZ}$ & 2 & -0.893897 & 0.31890 & -2.80308 & 0.997595 & 4.471224 & 4.558880 \\
$\mathrm{ZJ}$ & 2 & 0.301042 & 0.32093 & 0.93804 & 0.985321 & 2.511362 & 2.599017 \\
\hline
\end{tabular}

表 5 中反映出各组变量当中, 无论是 1 阶还是 2 阶滞后期, 其AIC和 $S C$ 的值都趋于平稳, 说明该VAR 模型较为稳定, 并且一阶滞后期下的AIC值最小, 由此可对上述三组变量进行脉冲响应分析。

2. 脉冲响应函数

基于VAR模型中的三组变量, 通过绘制脉冲响应函数对变量进行动态关系下的冲击影响分析, 如 下图2所示。

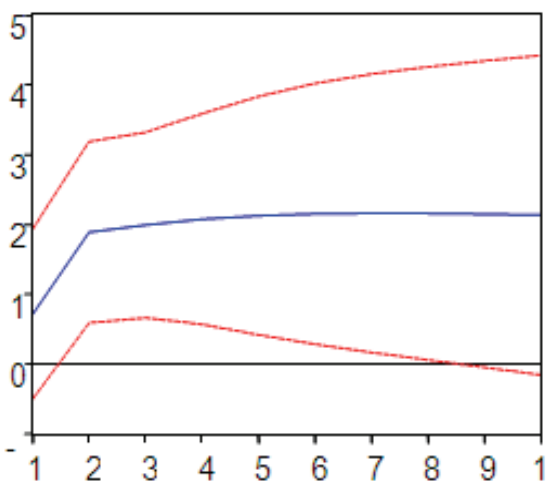

图 2（1）. 经济冲击对物流园区投资影响

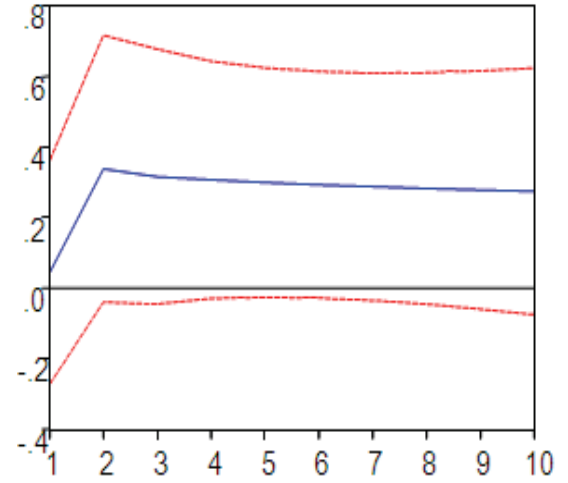

图 2（2）. 经济冲击对园区物流增加值影响 


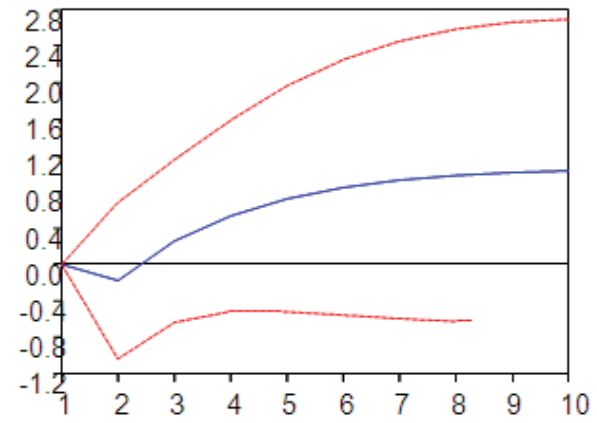

图 2（3）. 园区物流增加值冲击对物流投资影响

图2（1）反映了物流园区固定资产投资受到经济冲击的影响程度, 从图中可看出, 经济冲击对物流 园区投资的影响立即产生, 并且冲击程度超过 1 , 在前两个周期内, 县域经济发展对物流园区投资带来 的冲击效用迅速提升, 但其影响程度在第二个周期达到拐点, 在这之后, 其影响程度逐渐减弱, 并最终 趋于一条水平线，即县域经济对物流园区固定资产投资的冲击效应达到一种平衡。

图2（2）则反映了经济冲击对园区物流增加值的影响, 该模式与图（1）相类似，也在前两个周期 内冲击影响度逐步扩大, 第二个周期过后趋于平稳, 但其影响影响程度一直维持在较小的范围之内, 波 动幅度明显较小，经济冲击对园区物流增加值的影响也不是立刻就有反应。

图2（3）反映了园区物流增加值对物流投资的冲击影响, 在最初两个周期内, 园区物流增加值对物 流投资产生负向的冲击影响, 但第二个周期之后, 其影响程度呈现持续上升趋势, 说明园区物流增加值 对物流园区固定资产投资的短期效应不明显，但其对园区物流投资的长期影响较大。

\section{4 结论与建议}

\section{1 结论}

（1）黄冈市县域物流园区布局及“互联网+物流”发展问题。自从“物流业发展十三五规划”实施以来，物 流产业一直保持着较快的增长速度, “互联网+物流”也逐渐成为县级城市的重点发展方向, 过去十年黄 冈市县域物流园区发展取得了长足的进步, “互联网+物流”逐步发展, 但存在着总量小、规模小、布局 不合理等问题。

(2) “互联网 + ”下物流园区与县域经济发展存在关联性。物流园区固定资产投资、园区物流量、园 区物流增加值和地区生产总值四个时间序列变量间存在着平稳关系和协整关系，“互联网+”下物流 园区与县域经济存在长期稳定的互动关联关系。

(3) “互联网+”下物流园区与县域经济发展的螺旋关系。县域经济的发展促进物流园区固定资产投 资的增长, 带动园区物流量的提升, 促进 “互联网十物流” 的发展; 园区物流量的积累与集聚带动起规 模效应, 吸引资本的集聚, 实现物流园区固定资产投资的增长, 并通过产业投资推动县域经济的进一步 发展; 而县域经济又促进了园区物流增加值的提升, 进而推动 “互联网+物流” 发展, 如此循环往复, 促使 “互联网+物流”与县域经济发展呈螺旋式上升。

(4) “互联网 + ”下物流园区与县域经济发展的时间关系。园区物流增加值在短期内并短期不能给物 流固定资产投资带来显著提升, 但长期来看, 尤其是第二周期之后, 其对物流园区投资的影响越来越明 显; 县域经济发展能够在短期之内对物流园区固定资产投资以及物流增加值产生较大的冲击影响, 但其 影响效用并不能持久，尤其是在第二期之后，其影响程度逐渐减弱，并最终趋于平稳。

\section{2 建议}

为了充分发挥“互联网+”下物流园区对县域经济的促进作用, 加快“互联网+物流”发展, 对黄冈市县域 物流园区发展提出以下建议:

(1) “互联网+物流” 固定资产及基础设施建设投资。基于物流园区国定资产投资与县域经济存在双 向的格兰杰原因，建议加大对 “互联网+物流” 的招商引资力度，除政府资金投入外，积极整合现有的 “互联网+物流” 资源并布局新型现代化农贸物流市场, 充分发挥县域农产品的比较优势, 并科学引导 仓储设施的布局与建设。 
（2）基于物流园区进行 “互联网+物流” 产业的集聚。鉴于物流量的集聚能够带来更多的产业建设资 本，县域物流园区应打破各部门管理上存在的条块分割现状，促进物流资源在县域物流园区集聚。通过 对物流业发展的统筹规划、协调与规范管理, 明确物流业发展的责任主体，提高物流管理效率及专业化 水平，利用物流产业集聚效应提升 “互联网+物流”的发展效率。

（3） “互联网+”下县域物流园区间的紧密协作与互动。针对县域 “互联网+物流” 普遍存在的物流量 不足、“互联网+物流” 体系不完善等问题，物流园区间应积极加强合作，推动县域 “互联网+物流” 一体化发展。可将黄梅县作为黄冈市内河港口物流试点区进行重点培育, 以小池港为重点建设单位, 加 强与武汉、南昌等内河航运发达城市间的连接与合作; 在罗田县重点发展多式联运系统, 推动公铁联运, 依托较为密集的乡镇公路运输网，加快罗田农产品的外输，促进乡镇地区物流资源的集散。

致谢. 本文得到 2019 年湖北省教育厅人文社科项目、2018 年湖北省社科基金一般项目、武汉纺织大学 2018 年科技创新计划的资助，是其阶段性成果。

\section{参考文献}

1. 国务院.国家物流业发展十三五规划[R].[EB/OL]. http://www.guancha.cn /society/2016_03_17_354244.shtml.

2. 唐剑, 李虹. 民族地区交通运输与区域经济互动发展研究——以四川阿坝藏族芫族自治州为例 [J]. 经济体制改 革, 2015 (5) : 78-83.

3. 曹雷,李诚固,才德昊.基于“互联网+”的我国县域经济发展方式转变 $[J]$.税务与经济, 2017, (1):68-72.

4. 李剑,姜宝.物流产业集聚对区域经济增长影响研究——基于省际数据的空间计量分析 $[\mathrm{J}]$.中南大学学报(社会科学 版),2016,22(04):103-110+115

5. 陶经辉,王陈玉. 基于系统动力学的物流园区与产业园区服务功能联动 [J]. 系统工程理论与实践,2017,37(10):26602671.

6. 叶羽,许舒婷.物流园区对区域经济影响的评价体系构建 [J].物流技术, 2018,37(08):52-54+66.

7. 郭湖斌,齐源.基于耦合模型的长三角区域物流与区域经济协调发展研究 [J].工业技术经济,2018,37(10):51-58.

8. 朱长征,赵亮.物流产业集聚对区域经济影响的城市比较[J].商业经济研究,2018(18):99-101.

9. 杨琳.区域物流发展对县域经济的影响邹议[J].现代物流, 2016, (22):83-85.

10. 刘明菲,李兰.区域物流与区域经济互动作用机理分析[J].工业技术经济, 2007, (3):40-43.

11. 胡凯,甘䈗青,高阔.中部地区物流基础设施投资对经济发展作用的协整分析[J].科技进步与对策,2010,(24):56-59.

12. 刘俊华, 李瑶琴, 长青. 物流基础设施投资与经济增长关系研究——基于系统动力学与误差修正模型 $[\mathrm{J}]$. 华东经济管 理,2013,27(12):65-70.

13. 王欢欢.我国中部物流基础设施投资与区域经济增长协整分析 [J].物流科技,2015,38(08):91-94.

14. Taylor. Measuring service quality: A reexamination and extension [J]. Journal of marketing, 2012, (8):55-58.

15. Ozmen,zhay.analysis of transportation and ecnonmic development at state and county [J].Transportation, 2016, (2): $53-58$.

16. 刘春雷,孙宝佳,王军丽.临空物流与区域经济协同性分析 以武汉临空经济区为例 $[\mathrm{J}]$.现代商贸工业, 2017, (8):30-31.

17. 龙宇,徐常乐. 长江经济带物流业对区域经济发展影响的实证分析[J].物流科技, 2013, (12):65-68.

18. 于俊年.计量经济学软件- - EVIEWS 的使用 $[\mathrm{M}]$. 北京:对外经贸大学出版社,2012.

19. 李子奈.计量经济学教程 $[\mathrm{M}]$. 北京:清华大学出版社,2005.

20. 高铁梅. 计量经济分析方法与建模一一Eviews 应用及实例（第二版） [M].北京:清华大学出版社,2009:126-127. 